\title{
SISTEM INFORMASI ABSENSI BERBASIS WEB PADA BADAN PENANGGULANGAN BENCANA DAERAH KOTA TANGERANG
}

\author{
Mulyati ${ }^{1}$ \\ Rasyid Tarmizi ${ }^{2}$ \\ Angga Panugali ${ }^{3}$

\begin{abstract}
Dosen STMIK Raharja Tangerang ${ }^{1,2}$, Mahasiswa STMIK Raharja Tangerang ${ }^{3}$
Jl. Jenderal Sudirman No.40 Modernland Cikokol, Tangerang ${ }^{1,2,3}$

e-mail: mulyati@ $\underline{\text { raharja.info }}{ }^{1}$, rasyid@ raharja.info ${ }^{2}$, angga.panugali@ raharja.info ${ }^{3}$
\end{abstract}

\begin{abstract}
ABSTRAK
Badan Penanggulangan Bencana Daerah (BPBD) Kota Tangerang adalah lembaga pemerintahan non departemen yang bertugas menanggulangi bencana di wilayah Kota Tangerang yang berpedoman pada kebijakan Badan Nasional Penanggulan Bencana. Agar kinerja karyawan meningkat diperlukan inovasi di berbagai bidang. Salah satunya mengubah sistem absensi manual dengan sistem informasi absensi berbasis web agar kecurangan-kecurangan seperti pemalsuan tanda tangan dan pengisian jam kedatangan yang berbeda dapat diatasi. Sistem absensi berbasis web ini dirancang menggunakan software adobe dreamweaver CS6, visual paradigm for 6.4 enterprise edition, XAMPP. Setelah program jadi dilakukan pengujian dengan menggunakan black box. Data penelitian dikumpulkan dengan melakukan pengamatan, wawncara dengan pihak terkait, dan membaca buku dan literatur lainnya. Sistem absensi berbasis online ini lebih menghemat waktu dan memudahkan pihak terkait dalam mengelolah data sehingga informasi yang dihasilkan dapat lebih cepat, akurat, dan aman.
\end{abstract}

Kata kunci: Perancangan Sistem Informasi, Absensi, Berbasis Web

\begin{abstract}
The Regional Disaster Management Agency (BPBD) of Tangerang City is a non-departmental government agency tasked with tackling disasters in the Tangerang City region that is guided by the National Disaster Management Agency's policy. In order to increase employee performance requires innovation in various fields. One of them changed the manual absence system with web-based attendance information system so that fraud such as signature falsification and different arrival time filling can be overcome. This web-based attendance system is designed using adobe dreamweaver CS6 software, visual paradim for 6.4 enterprise edition, XAMPP. After the program finished tested using black box. Research data was collected by observing, interviewing with related parties, and reading books and other literature. Online-based attendance system is more time saving and facilitate the relevant parties in managing the data so that the information produced can be more quickly, accurately, and safely.
\end{abstract}

Keyword: Information System Design, Web-based Member Attendance List System

\section{PENDAHULUAN}

Badan Penangulan Bencana Daerah (BPBD) Kota Tangerang merupakan badan pelayanan masyarakat dengan memiliki visi mewujudkan BPBD yang profesional untuk menjadikan masyarakat Kota Tangerang tangguh dalam menghadapi bencana. Untuk mewujudkan visi tersebut diperlukan sumber daya manusia yang memiliki disiplin yang tinggi. Salah satu indikator disiplin kerja adalah para karyawan hadir di kantor tepat waktu, 
tertib, dan teratur. Untuk memantau dan mengawasinya dibutuhkan inovasi dengan memperbaiki sistem manajemen kehadiran karyawan agar produktivitas dan pengembangan diri karyawan dapat meningkat lebih baik, efektif, dan efisien.

Sistem absensi manual dapat menimbulkan kecurangan seperti tanda tangan dipalsukan dan jam kedatangan yang berbeda sehingga data absensi tidak akurat ini akan berpengaruh pada penghitungan pembayaran gaji dan upah lembur karyawan. Jika dibiarkan berlanjut terus akan membahayakan angggaran perusahaan dan mengurangi tingkat kedisiplinan dan menurunkan kinerja karyawan.

Berdasarkan hal itulah, perusahaan membutuhkan sebuah sistem absensi berbasis web sehingga memudahkan bagian seksi kepegawaian dalam mengelolah data absensi para anggota Badan Penangulan Bencana Daerah (BPBD) Kota Tangerang.

\section{PERMASALAHAN}

Selain menimbulkan kecurangan, informasi data yang tidak valid, pengelolaan data secara manual memungkinkan terjadi kesalahan dalam merekap data kehadiran dan proses pencariannya tidak efisien karena harus mencari dalam tumpukan berkas arsip.

\section{METODE PENELITIAN}

Ada empat metode yang digunakan yaitu metode pengumpulan data, metode analisis, metode perancangan, dan metode pengujian.

\section{Lokasi dan Waktu}

Penelitian dilakukan di bagian divisi kepegawaian Badan Penanggulangan Bencana Daerah Kota Tangerang selama enam bulan mulai Juli 2016 s.d. Februari 2017.

\section{Pengumpulan Data}

\section{Observasi}

Mengamati prosedur absensi dan pengolahan data ke bagian kepegawaian Badan Penanggulangan Bencana Daerah Kota Tangerang.

2. Wawancara (Interview)

Mewawancarai kepala bagian kepegawawaian terkait kebutuhan sistem absen berbasis web. 3. Studi Pustaka (Library Research) Mengumpulkan data-data dengan membaca buku-buku, artikel, jurnal ilmiah, dan website terkait perancangan absensi berbasis web.

\section{Metode Analisis Sistem}

SWOT (Strenghts-Weaknesses-Opportunities-Treats) merupakan metode perancanaan strategis yang digunakan untuk mengevaluasi kekuataan, kelemahan, peluang, dan ancaman dari suatu proyek.

\section{Metode Perancangan}

Metode waterfall digunakan untuk menganalisis sistem absensi yang diusulkan melalui tahapan-tahapan berurutan atau liner mulai dari tahap analisis, desain, penulisan, pengujian, penerapan, sampai ke tahap pemeliharaan. 


\section{Tinjauan Pustaka}

\section{Definisi Sistem}

Sistem didefinisikan sebagai serangkaian tindakan yang saling berhubungan dan berkaitan untuk melkukam dan mencapai tugas bersama-sama.[1]

Kata 'sistem' mengandung arti kumpulan dari komponen-komponen yang memiliki unsur keterkaitan antara satu dan lainnya. [2]

\section{Definisi Informasi}

Informasi adalah sebuah nilai, arti atau manfaat yang dihasilkan dari proses pengolahan berbagai sumber data [3]

Informasi adalah suatu pertambahan dalam ilmu pengetahuan yang menyumbangkan kepada konsep kerangka kerja yang umum dan fakta-fakta yang diketahui. [4]

\section{Definisi Absensi}

Absensi adalah dokumen kehadiran yang berisi daftar nama, jam kedatangan, jam perpulangan, dan keterangan sebagai pedoman untuk penghitungan pembayaran gaji.[5]

Absensi adalah suatu cara untuk mengetahui sejauh mana tingkat disiplin kerja, apakah orang yang bekerja mampu mentaati peraturan yang berlaku. Absensi adalah unsur kedisiplinan yang bertujuan untuk meningkatkan kedisiplinan dalam sebuah institusi.[6]

\section{Definisi UML (Unified Modelling Language)}

UML adalah bahasa visual untuk pemodelan dan pengomunikasian sistem dengan menggunakan diagram dan teks-teks pendukung. [7]

"Unified Modeling Language or UML is defined as a standar dized general purpose modeling language in the field of object oriented software engineering". Yang artinya Unified Modeling Language atau UML didefinisikan sebagai bahasa pemodelan tujuan umum yang dirancang khusus dalam bidang rekayasa perangkat lunak berorientasi objek.[8]

\section{Definisi Perancangan Sistem}

Perancangan sistem adalah termasuk bagaimana mengorganisasi sistem ke dalam subsistem-subsistem, perangkat keras, perangkat lunak serta prosedur-prosedur. [9] perancangan merupakan spesifikasi umum dan terinci dari pemecahan masalah berbasis komputer yang telah dipilih selama tahap analisis.[10]

\section{HASIL DAN PEMBAHASAN}

Hasil rancangan pengelolaan data absensi berbasis web ini lebih mudah digunakan karena sistem menyediakan fasilitas pencetakan laporan-laporan, menu search, dan lainnya sehingga memudahkan user menggunakannya. Kelebihan lainnya, menjaga privasi dan data absensi sehingga data yang dihasilkan lebih akurat karena setiap karyawan memiliki usernama dan pasword untuk bisa $\log$ in ke sistem. Setelah data absensi anggota BPBD masuk, staf dan kasubag kepegawaian dapat memantau data absensi untuk dibuatkan laporan perhitungan gaji.

\section{Use Case Diagram}

Tampilan Use case diagram usulan tampak seperti berikut ini: 


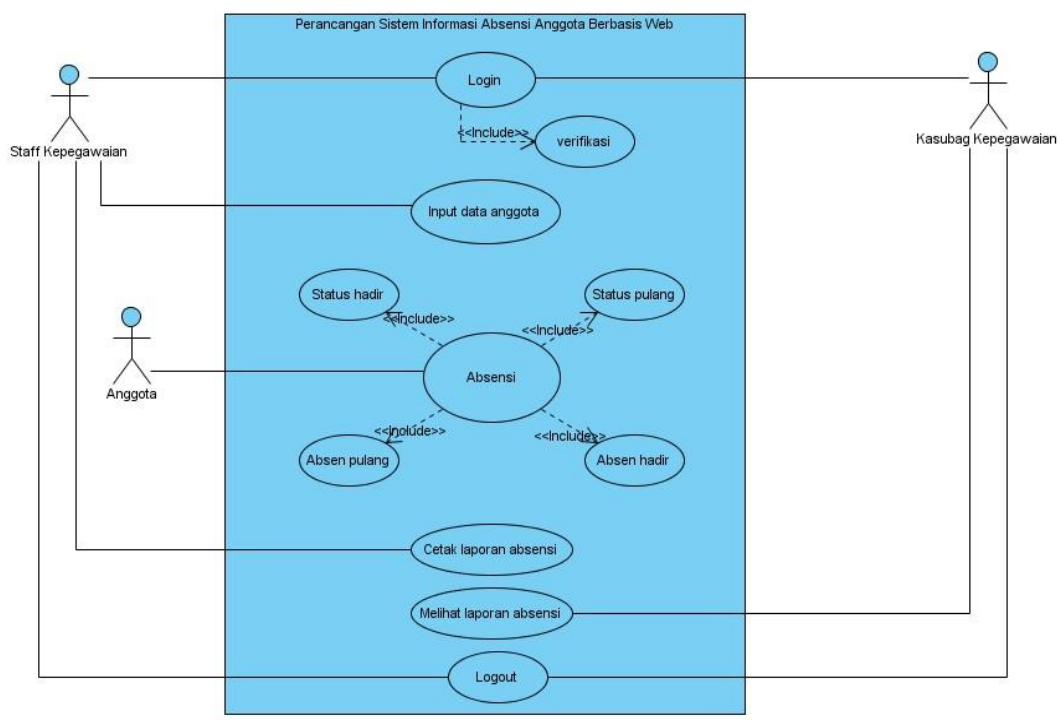

Gambar 1. Use Case Diagram Absensi Anggota BPBD Kota Tangerang yang Diusulkan.

Berdasarkan gambar di atas, bagian use case tersebut dapat dijabarkan seperti di bawah ini:

1. Satu sistem yang menggambarkan seluruh proses kegiatan absensi anggota BPBD.

2. Tiga aktor yang terlibat dalam aktivitas sistem yaitu staf kepegawaian, anggota, dan kasubag kepegawaian.

3. Enam use case yang menjelaskan interaksi antara aktor dengan sistem seperti login, input data anggota, input data grup, absensi, cetak laporan absensi, melihat laporan absensi, dan logout.

4. Lima include, yaitu : Verifikasi login, absen hadir, absen pulang, status hadir, status pulang.

5. Lima include, yaitu : Verifikasi login, absen hadir, absen pulang, status hadir, status pulang.

\section{Sequence Diagram Sistem yang Diusulkan}

Sequence diagram yang diusulkan untuk absensi anggota sebagai berikut :

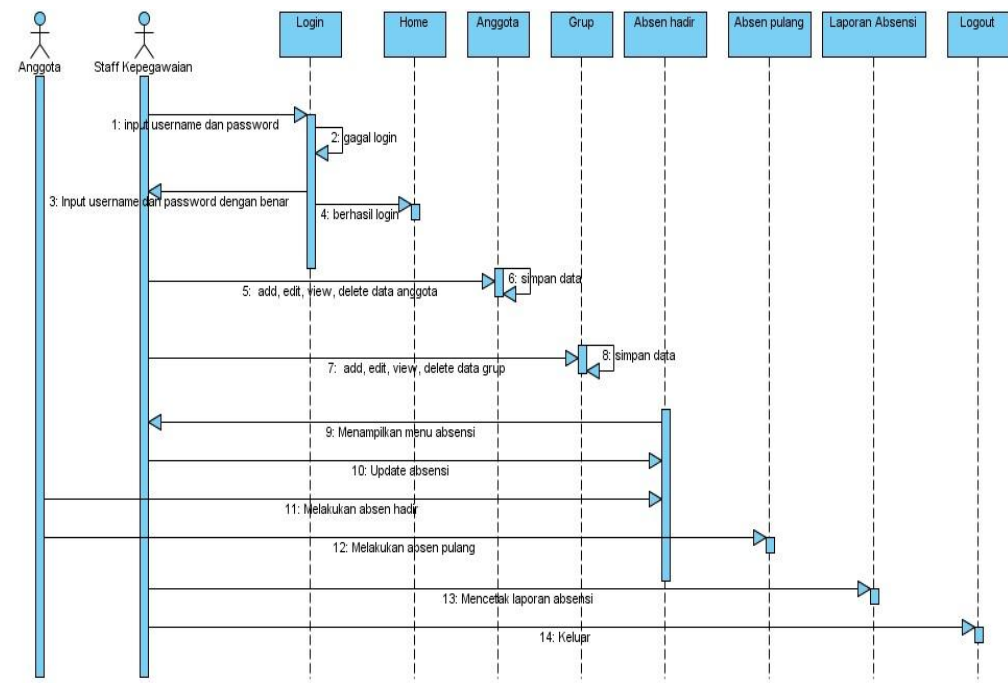

Gambar 2. Sequence Diagram Absensi Anggota. 
Berdasarkan gambar 2 Sequence Diagram yang Diusulkan terdapat:

1. Absensi anggota. Dari gambar di atas, terdapat:

2. Delapan lifeline antarmuka yang saling berhubungan

3. Dua actor yang dapat mengakses sistem absensi yaitu anggota dan staff kepegawaian.

4. Sebelas messages yang berisi informasi aktivitas yang dilakukan oleh aktor

5. Tiga self messages untuk pemanggilan konsep object itu sendiri.

\section{Sequence Diagram yang Diusulkan}

Sequence diagram yang diusulkan untuk Kasubag Kepegawaian, sebagai berikut :

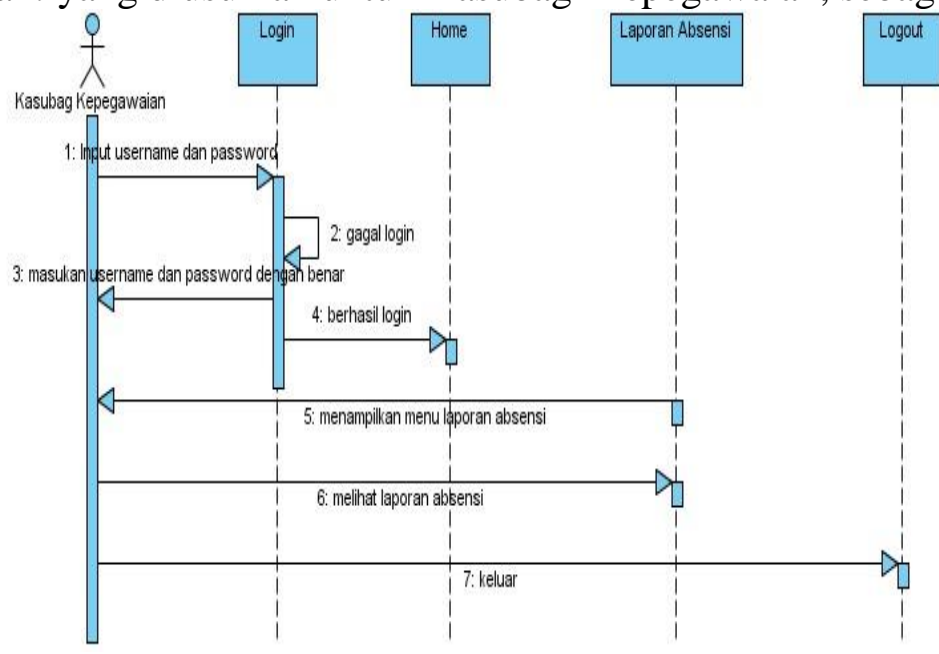

Gambar 3. Sequence Diagram Sistem yang Diusulkan

Berdasarkan gambar 3. sequence diagram yang diusulkan terdapat:

1. Empat LifeLine antar muka yang saling berhubungan.

2. Satu actor yaitu Kasubag kepegawaian

3. Enam messages berisi informasi kegiatan yang dapat dilakukan aktor

4. Satu self messages untuk pemanggilan konsep object itu sendiri.

\section{Activity Diagram yang Diusulkan untuk Anggota}

Activity diagram yang diusulkan untuk anggota, sebagai berikut

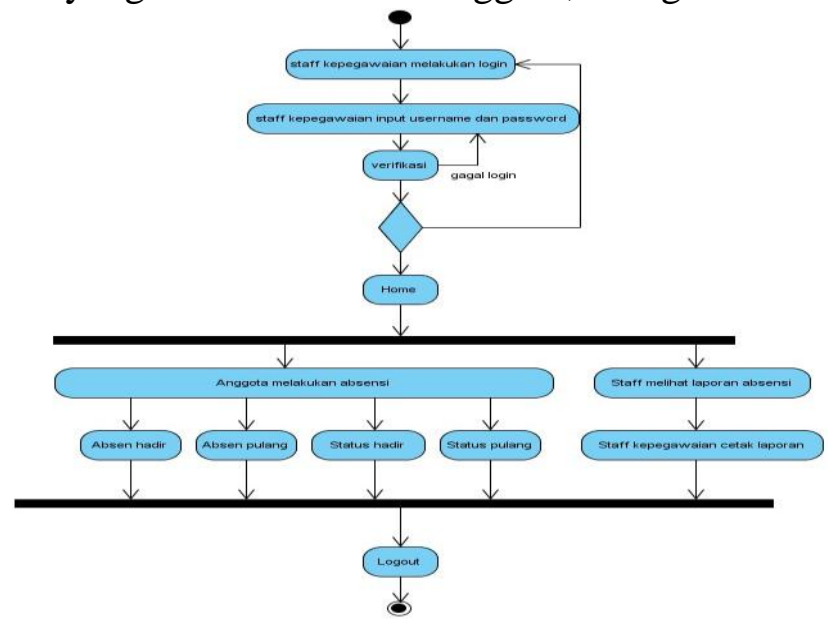

Gambar 4. Activity Diagram Sistem yang diusulkan untuk Anggota 
Berdasarkan gambar di atas terdapat:

1. Satu initial node untuk mengawali objek

2. Dua actor yaitu staff kepegawaian dan anggota.

3. Dua belas activity yang dapat dikerjakan oleh actor

4. Satu decision node

5. Dua join node

6. Satu activity final node menjelaskan bahwa objek dibentuk.

\section{Activity Diagram yang Diusulkan untuk Kasubag Kepegawaian}

Activity diagram yang diusulkan untuk kasubag kepegawaian, sebagai berikut:

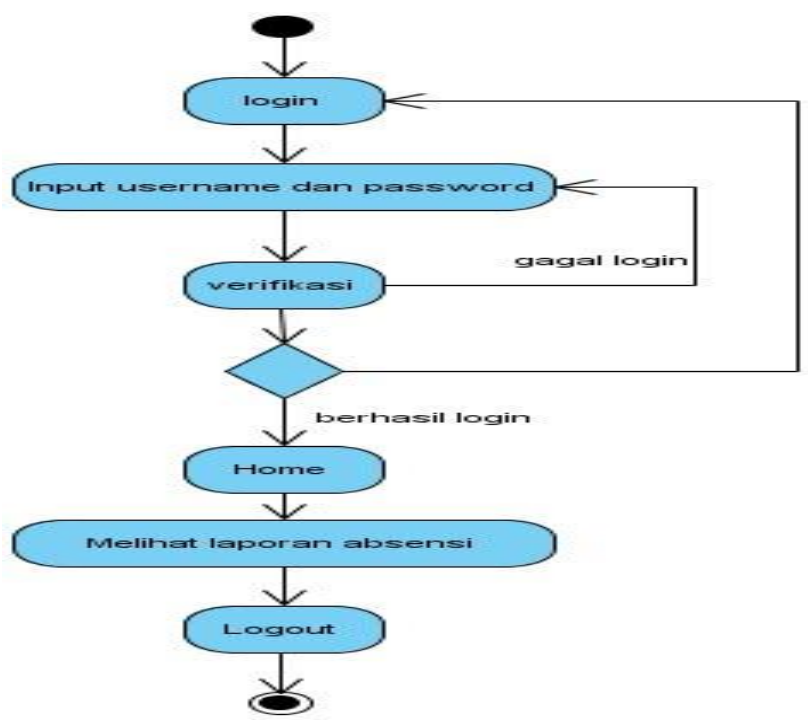

Gambar 5. Activity Diagram Sistem yang diusulkan untuk kasubag kepegawaian

Berdasarkan gambar di atas terdapat:

1. Satu initial node untuk mengawali objek.

2. Satu actor yaitu Kasubag Keuangan

3. Enam action activity yang dilakukan oleh actor

4. Satu decision node

5. Satu activity final node untuk mengakhiri objek.

\section{Class Diagram yang Diusulkan} logika.

Class diagram menunjukkan class yang terdapat dalam sistem dan hubungannya secara

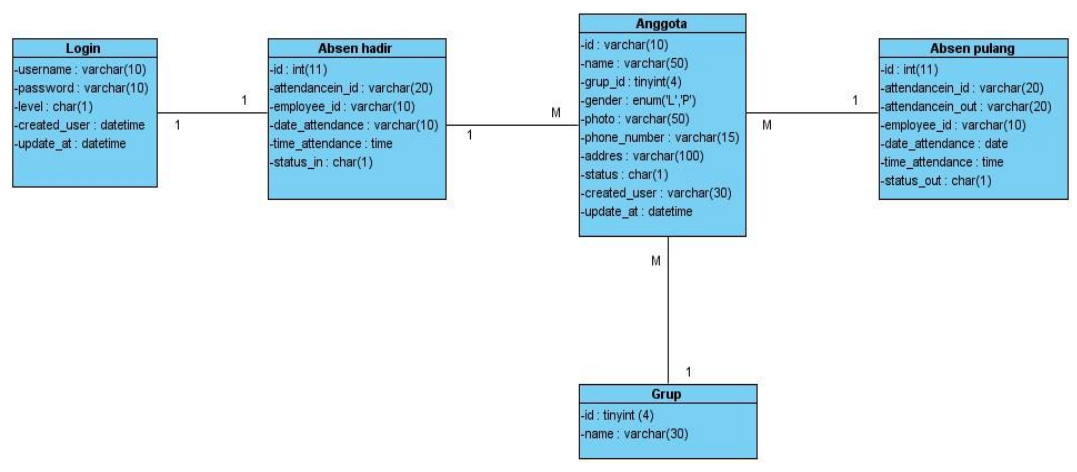

Gambar 6. Class Diagram Sistem yang diusulkan. 


\section{Implementasi Program}

Tampilan Web Login

Tampilan login yang wajib diisi oleh user dengan memasukkan username dan password

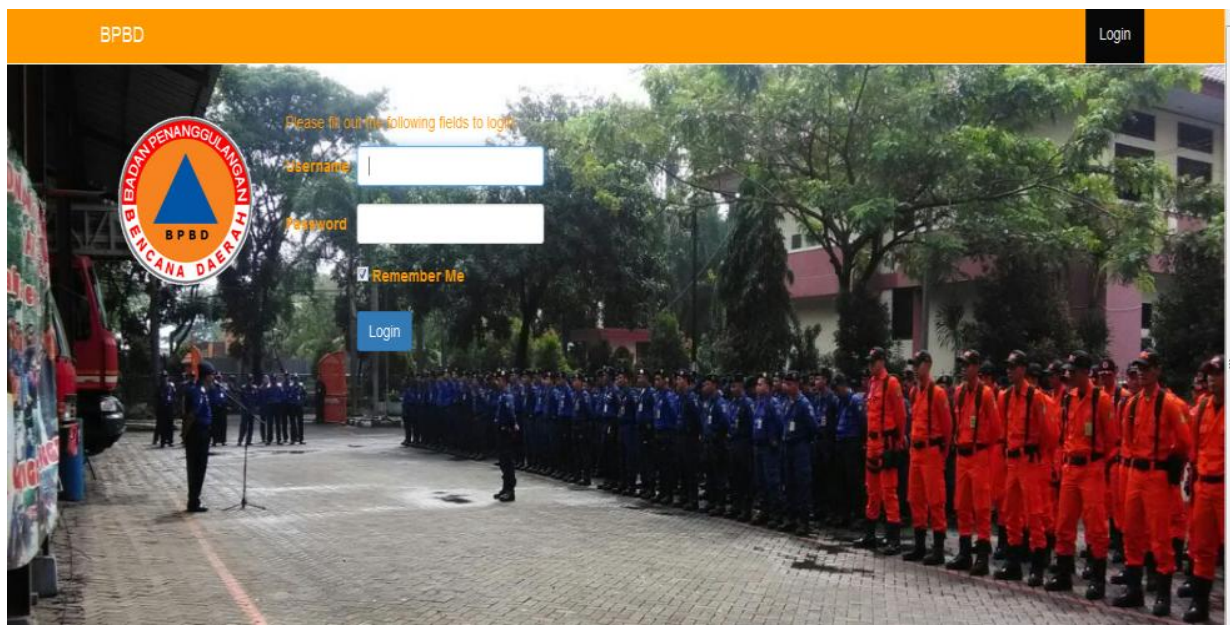

Gambar 7. Tampilan Rancangan Web Login

Tampilan Web Halaman Utama

Berisi menu atau icon-icon yang berhubungan dengan absensi seperti icon setting, report, employee, dll.

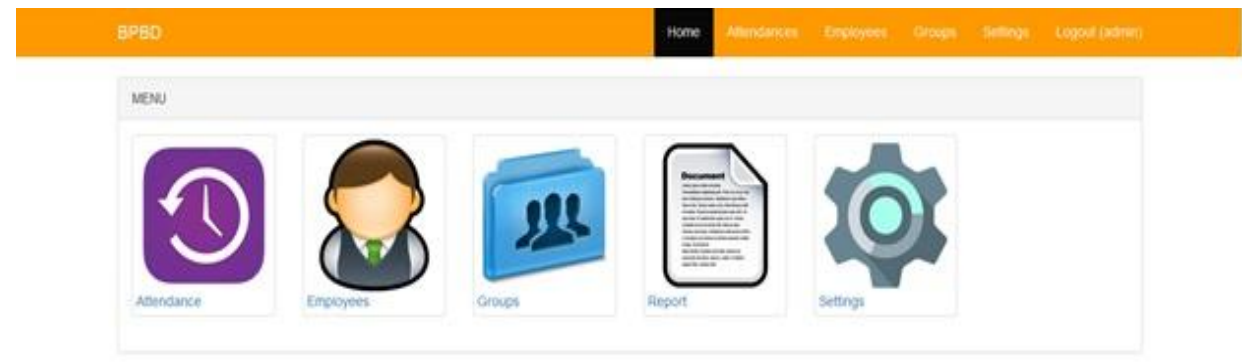

Gambar 8. Tampilan Rancangan Web Halaman Utama

Tampilan Web Menu Absensi Anggota

Menu absensi anggota beserta field-field nya yang berhubungan dengan absensi. 


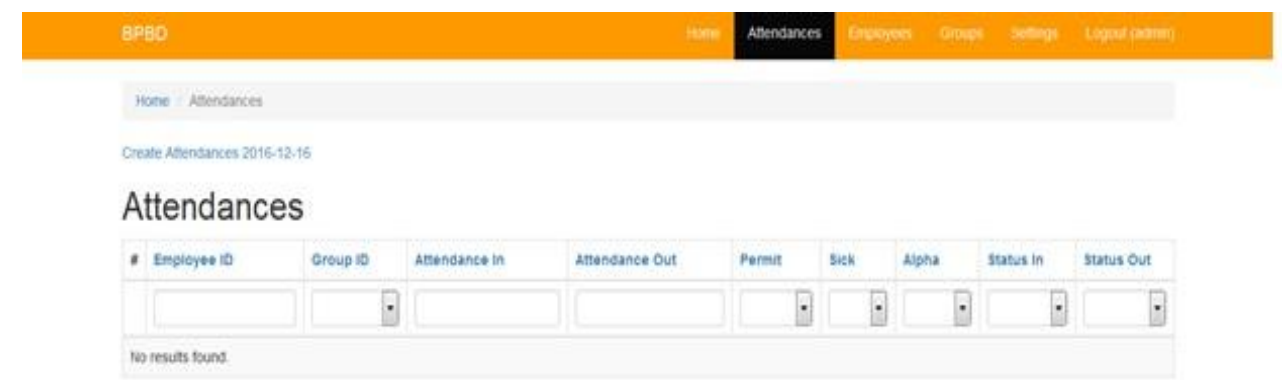

\section{$\cos x \sin$}

Gambar 9. Tampilan Rancangan Web Menu Absensi Anggota

Tampilan Web Menu Anggota

Tampilan program ini berisi tampilan data anggota beserta fotonya agar mudah dikenali.

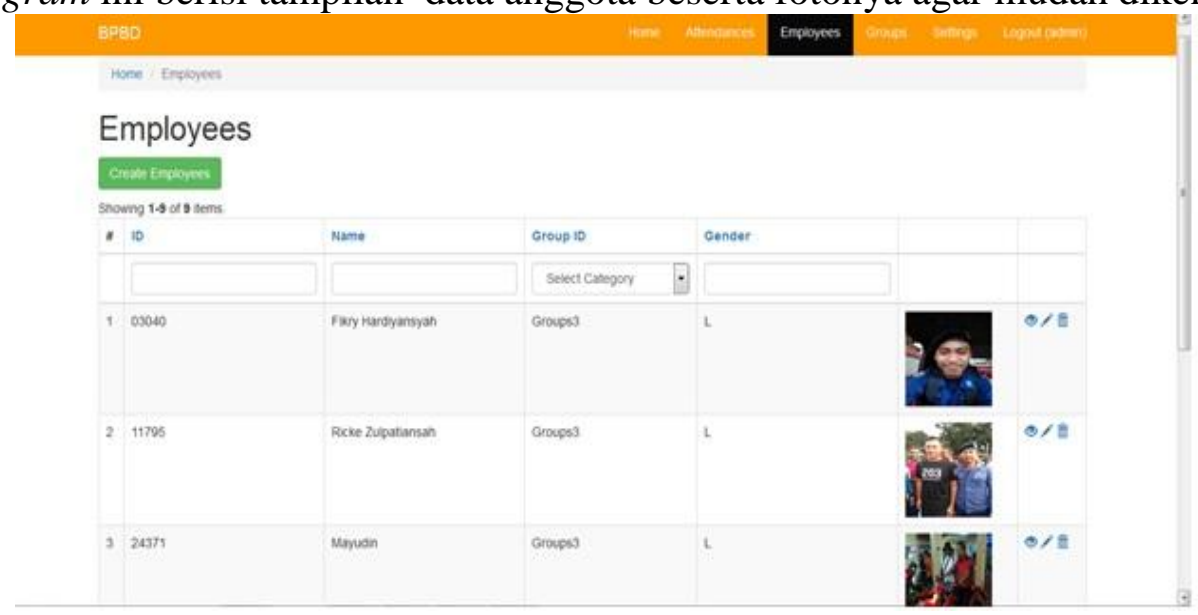

Gambar 10. Tampilan Rancangan Web Menu Anggota

Tampilan Web Menu Grup

Berisi jumlah grup yang terdapat pada sistem.

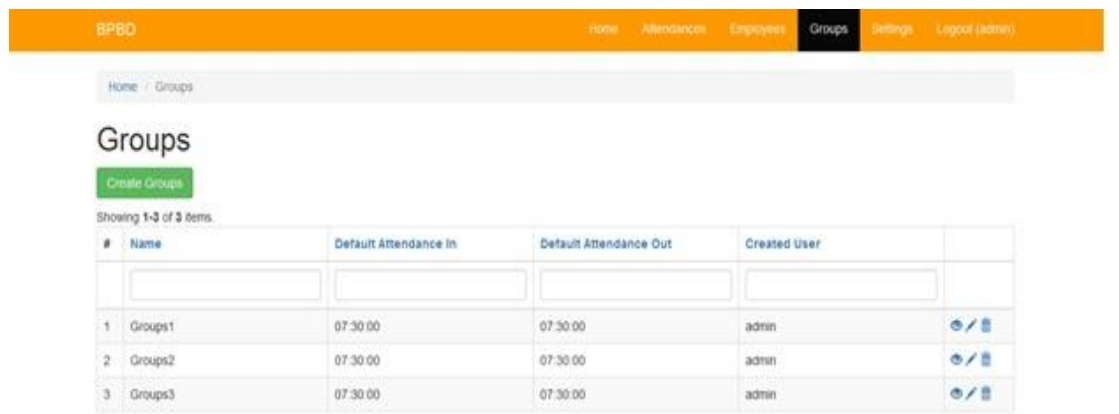

Gambar 11. Tampilan Rancangan Web Menu Penyusutan 
Tampilan Web Tampilan Web Menu Laporan

Berisi tampilan laporan absensi tiap bulannya.

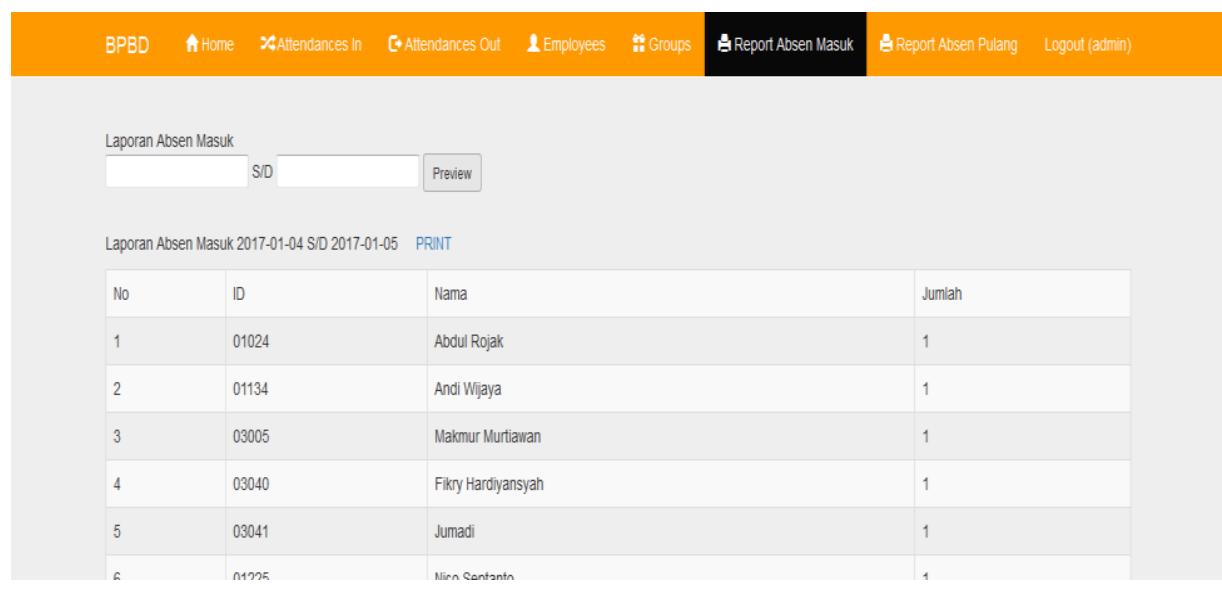

Gambar 12. Tampilan Rancangan Web Tampilan Web Menu Laporan

\section{Testing}

Metode black-box testing untuk memastikan bahwa program sistem yang telah dibuat apakah masih terdapat kesalahan atau tidak. Dari setiap tes pengujian ini tidak menutup kemungkinan masih adanya kesalahan dari sistem yang telah di tes, tetapi pengujian ini setidaknya dapat meminimalisir kesalahan fungsionalitas program yang terdapat di dalam sistem.

Tabel 1. Black Box Testig

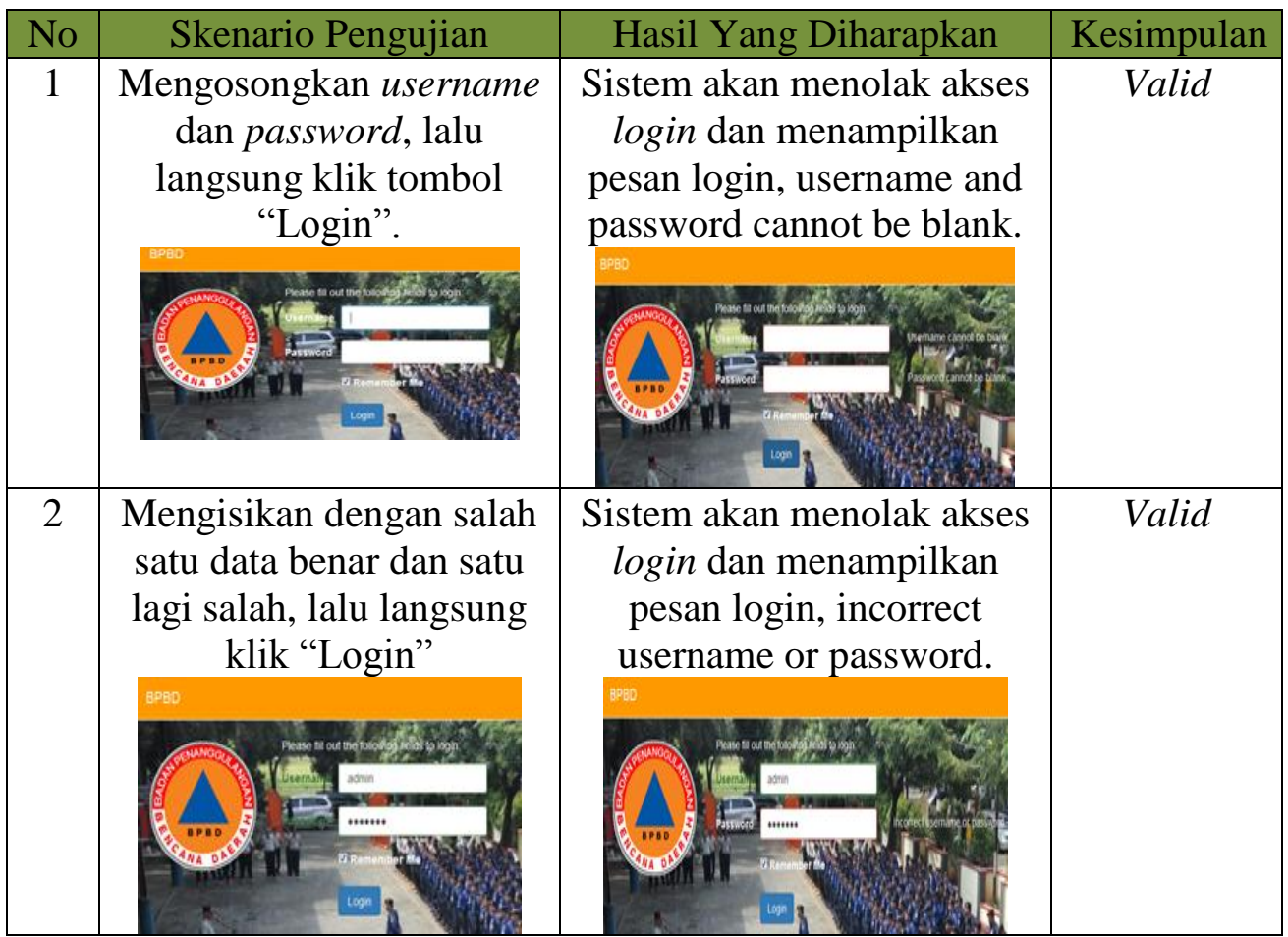




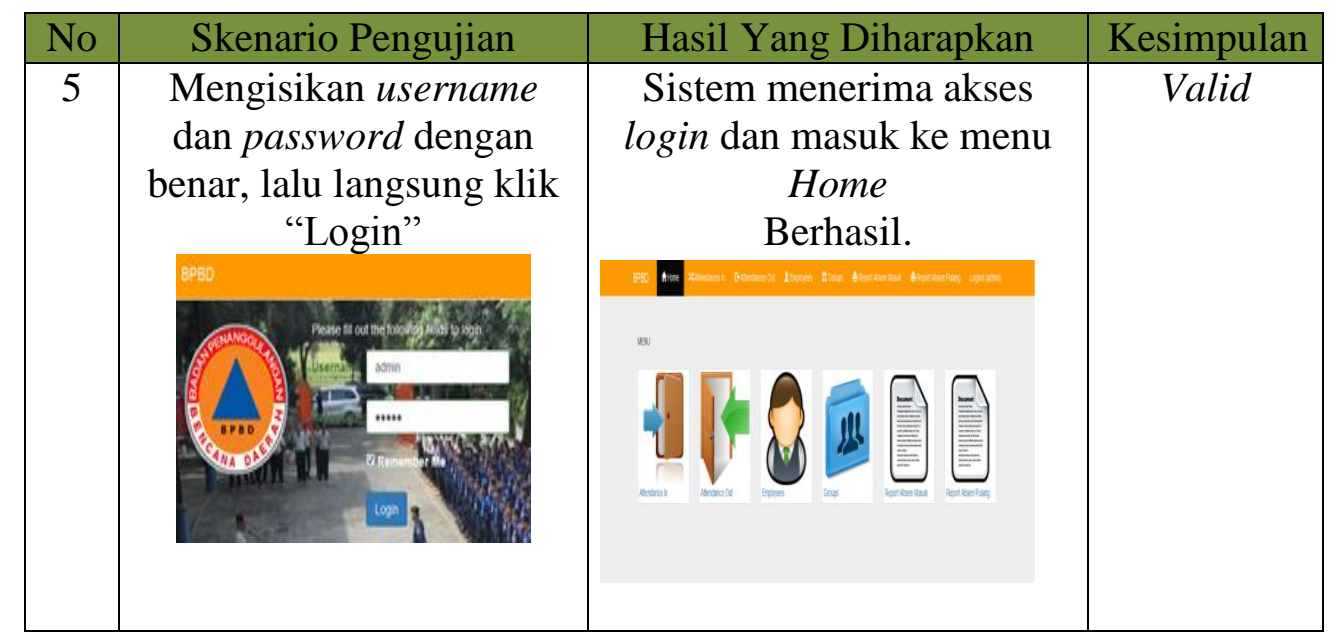

\section{KESIMPULAN}

Pengolahan data absensi anggota Badan Penanggulangan Bencana Daerah Kota Tangerang masih manual dengan mengisi form yang telah tersedia sehingga penyimpanan laporan data absensi belum terlaksana dengan baik, data yang dihasilkan tidak akurat karena banyak terjadi manipulasi data, penyimpanan data dalam tumpukkan arsip menyebabkan kesulitan dalam pencarian, bahkan bisa terjadi kerusakan dan kehilangan data.

Perancangan sistem informasi absensi berbasis web dibuat sebagai solusi memudahkan dan mempercepat proses absensi, serta melakukan penyimpanan data dengan akurat. Rancangan sistem digambarkan dengan UML diantaranya use case diagram, activity diagram, dan class diagram dengan aplikasi visual paradigm. Selanjutnya menjabarkan tabel-tabel yang ada di dalam databse pada spesifikasi basis data, bahwa database tersebut dibuat menggunakan MySQL.

\section{SARAN}

Berdasarkan hasil penelitian, penulis memberikan saran : Perlu dilakukan pemeliharaan dan pencatatan ketika terjadi kendala dan permasalahan pada sistem sehingga kesalahan dapat segera diatasi; Dalam penggunakan sistem informasi absensi diperlukan ketelitian dari pengguna terutama dalam pengoperasian dan penyimpanan hendaknya sesuai dengan prosedur yang ada; Perlu adanya pengembangan sistem secara berkelanjutan, terutama untuk meminimalisir kekurangan-kekurangan yang ada pada proses absensi sehingga sistem dapat selalu up to date.

\section{DAFTAR PUSTAKA}

[1] Pratama, I.P A. E. (2014). Sistem Informasi dan Implementasinya ( $1^{\text {st }}$ ed.). Bandug: Informatika Bandung.

[2] Swastika, I. P. A., \& Putra, I. G. L. A. R, Audit Sistem Informasi dan Tata Kelola Teknologi Informasi: Implementasi dan Studi Kasus. Yogyakarta: Andi, 2016.

[3]Hutahaean, J, (2015) Konsep Sistem Informasi. Yogyakarta: Deepublish.

[4]Tyoso, Sistem Informasi Manajemen. Yogyakarta: Deepublish, 2016.

[5]https://www.scribd.com/doc/84061421/Sistem-Informasi-Manajemen-Absensi. 
[6]Santoso, S. (2016). Perencanaan Dan Pembuatan Aplikasi Absensi Dosen Menggunakan Radio Frequency Identification (RFID)(Studi Kasus Politeknik Negeri Tanah Laut). Prosiding SENIATI, (Book-2).

[7]Safudin, Mahmud. Jurnal Masyarakat Informatika Indonesia (JMII Vol 1/IV/2016) JMII Vol 2, No. 1, Januari-Maret 2017 ISSN: 2541-5093.

[8]Lee, Sunguk, "Unified Modeling Language (UML) for Database Systems," International Journal of Database Theory and Application, vol. 5, no. 1, p. 158, March 2012.

[9]Indraswuri, I. D, "Analisis Dan Perancangan Sistem Informasi Pelaporan Bantuan Operasional Sekolah Unit Pelaksana Teknis Taman Kanak-Kanak dan Sekolah Dasar (UPT TK Dan SD) Kecamatan Kebonagung," Speed-Sentra Penelitian Engineering dan Edukas, vol. 7, no. 3, 2013.

[10]Syukron, A., \& Hasan, N, "Perancangan Sistem Informasi Rawat Jalan Berbasis Web pada Puskesmas Winong," Bianglala Informatika, vol. 3, no. 1, 2015. 